\title{
Assessment of hospital pharmacists' clinical knowledge and practical skill levels for pharmaceutical care in Madinah, Saudi Arabia
}

\author{
Syed Wasif Gillani ${ }^{1}$, Mohi Iqbal Mohammad Abdul ${ }^{1}$, Irfan Altaf Ansari ${ }^{2}$, Hisham \\ A Zaghloul', Syed Ata-ur Rahman ${ }^{1}$, Mirza R Baig ${ }^{3}$ \\ ${ }^{1}$ College of Pharmacy, ${ }^{2}$ College of Medicines, Taibah University, Al Madinah Munawarrah, Kingdom of Saudi Arabia, ${ }^{3}$ Dubai \\ Pharmacy College, Dubai, United Arab Emirates
}

*For correspondence: Email: wasifgillani@gmail.com; Tel: +966538419573

Sent for review: 9 December 2017

Revised accepted: 27 January 2018

\begin{abstract}
Purpose: To evaluate hospital pharmacists' clinical knowledge and practical skill levels for pharmaceutical care.

Methods: A quasi-experimental prospective longitudinal study design was used to evaluate the level of clinical skills with problem-based learning (PBL) sessions. Pharmacists' in three different government hospitals in Madinah, Saudi Arabia recorded their responses or assessments in their work manuals for preparing reports. Instructors encouraged interactive learning by presenting case studies, in which pharmacists had to interpret medical history and clinical assessments of various body systems. Course learning design also focused on drug use evaluation, monitoring plans, and reaching clinical evidencebased decision-making.

Results: A total of two hundred and fifty-five (255) hospital pharmacists participated in the study. The study sample was comprised of $128(50.9 \%)$ males and $127(49.1 \%)$ females. A significant $(p<0.01)$ difference was noticed between genders (male: $47.91 \pm 7.15$, female: $50.31 \pm 4.88$ ) for total mean scores of clinical skills. Cronbach's alpha reliability coefficient for case data recitation was 0.91 , while clinical assessment skills coefficient was 0.89 . Overall, pharmacists reported that they "agree" $4.01 \pm$ 0.67) that they acquired the ability to use case data recitation taught in the PBL; they also reported a positive evaluation (4.48 \pm 0.58 ) of their ability to perform clinical data assessment.

Conclusion: The findings indicate that pharmacist's self-confidence to perform clinical assessment activities is low. Lack of confidence remains a critical education issue among pharmacists in the study setting.
\end{abstract}

Keywords: Clinical pharmacy, Problem-based learning, Clinical skills, Pharmacist focus group, Therapeutics, Pharmaceutical care

This is an Open Access article that uses a funding model which does not charge readers or their institutions for access and distributed under the terms of the Creative Commons Attribution License (http://creativecommons.org/licenses/by/4.0) and the Budapest Open Access Initiative (http://www.budapestopenaccessinitiative.org/read), which permit unrestricted use, distribution, and reproduction in any medium, provided the original work is properly credited.

Tropical Journal of Pharmaceutical Research is indexed by Science Citation Index (SciSearch), Scopus, International Pharmaceutical Abstract, Chemical Abstracts, Embase, Index Copernicus, EBSCO, African Index Medicus, JournalSeek, Journal Citation Reports/Science Edition, Directory of Open Access Journals (DOAJ), African Journal Online, Bioline International, Open-J-Gate and Pharmacy Abstracts

\section{INTRODUCTION}

Pharmaceutical science has gradually transitioned from the professional activities and responsibilities of traditional pharmacy tasks (e.g., compounding and dispensing) to patientcentered care services. Hepler [1] developed the concept of pharmaceutical care as a clinical practice philosophy that includes all pharmacy services necessary for patient care in order to 
attain definite outcomes and assure effective drug use, which improves the quality of life. The American Society of Hospital Pharmacists [2] declares pharmaceutical care service as a primary mission of the pharmacist. Extensive clinical research and practice implementation projects have proven the benefits of pharmaceutical care service in patient management, care and clinical outcomes [3].

Pharmacy educators are responsible for developing clinical skills among pharmacists in order to increase competency and confidence as they implement pharmaceutical care in their future practice [2]. In addition, pharmacists' must gain experience through ample clinical situations or scenarios to develop clinical knowledge foundation and practice effective communication skills necessary to serve the needs of patients in different healthcare settings [4]. Pharmaceutical care is the patient-centered care in which the 'Pharmacists' Patient Care Process' is involved. It includes collecting, assessing, planning, implementing, and follow-up monitoring \& evaluating information about patient progress [4]. Education research suggests that it is evenly important to enhance pharmacist positive attitudes and motivation to practice pharmaceutical care [5].

The American Accreditation Council for Pharmacy Education (ACPE) supports curricular models of instruction that employ an 'IntroduceReinforce-Demonstrate" approach to continous professional development (CPD); this helps the pharmacist to make connections between scientific understanding and patient care. It also assists with the evaluation of developing knowledge and application skills [6].

The concept of pharmaceutical care requires a balance of clinical knowledge, practical skills, and a professional attitude. Therefore, the aim of this study was to evaluate gender difference in hospital pharmacists' clinical knowledge and practical skill levels for pharmaceutical care, as well as measure the pharmacists' perception of usefulness of PBL method and confidence levels toward providing quality care after PBL.

\section{METHODS}

\section{Professional design and setting}

A prospective longitudinal study design was used to evaluate the level of clinical skills with problem-based learning (PBL) sessions (Figure 1). Pharmacists' from three different government hospitals in Madinah, Saudi Arabia recorded their responses or assessments in their pharmacist work manuals for preparing reports.

Table 2 shows mean score pattern among the study population (see Figure 2).

The trainer to pharmacist ratio was: 1: 6 (Pharmacy Accreditation Committee recommends 1: 8 ratio for clinical courses).

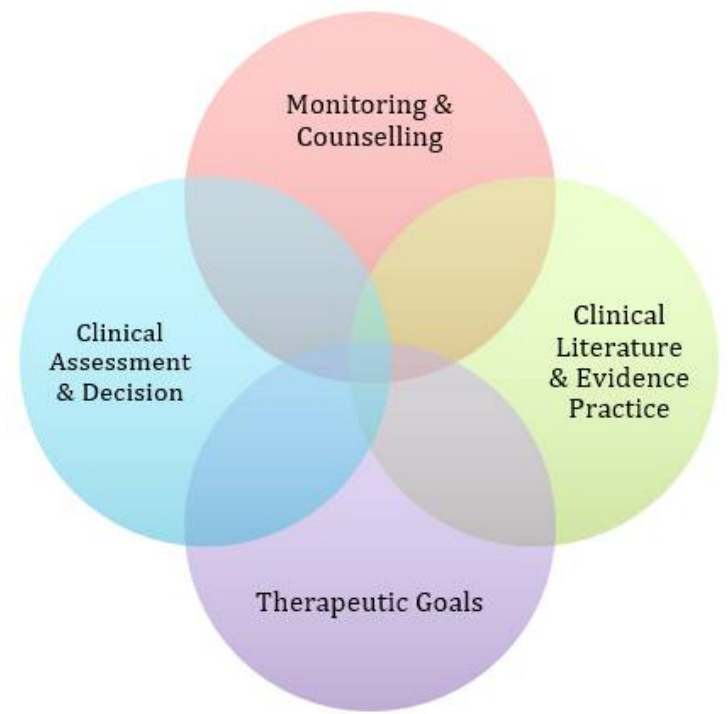

Figure 1: Theoretical framework for Problem-based learning $(\mathrm{PBL})$

\section{Ethical approval}

This study was approved by the Taibah University human research ethics committee (no. TUCD-17-10027) and was performed in compliance with the World Medical Association Declaration of Helsinki: Ethical principles for medical research involving human subjects, as amended by $59^{\text {th }}$ WMA meeting, 2013, Seoul, Korea (no. PHRC/HC/11/13).

All the pharmacists enrolled in this study signed the consent form at the time of enrollment.

\section{Instructional approach}

Instructors (principal investigator and team) facilitated interactive learning by detailing the medical histories and clincial assessment of the presented cases in $\mathrm{PBL}$ sessions. Interactive session also implemented different teaching techniques like using slides and audio-visual presentations. Various commom diseases, their physical findings such as hepatomegaly, lung sounds, types of tremors were emphasised for each case with the aim to relate to the drug therapy decision-making. The course design (7series of workshops in 2 months' duration) also focused on drug use evaluation, monitoring 


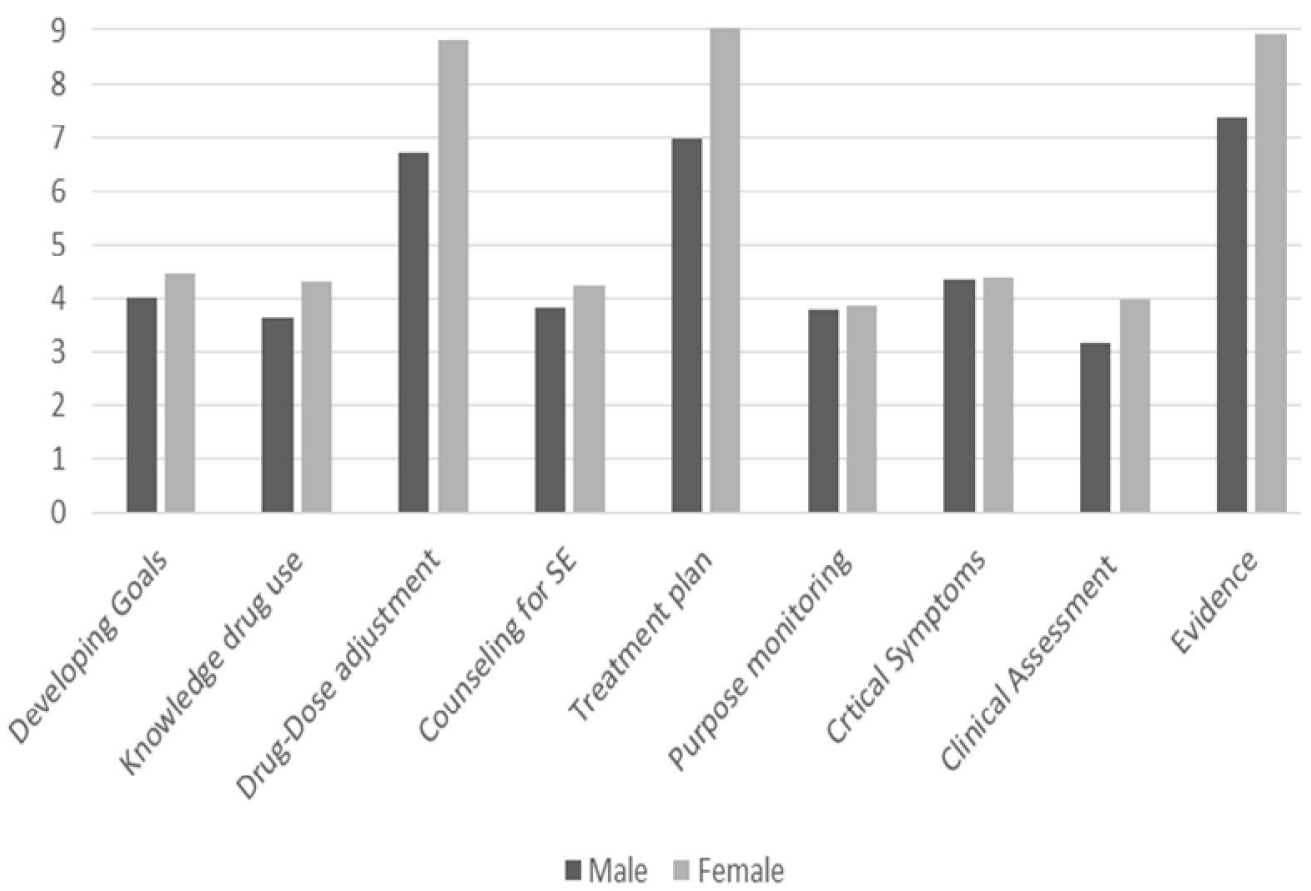

Figure 2: Mean score pattern among pharmacists

plans, clinical decision making, and finding the clinical evidence to support the decision. Following with demonstrations by instructors' pharmacists were given opportunity to perform the tasks individually subject to evaluation of their understanding.

\section{PBL-cases}

Pharmacists had several didactic lecture sessions to learn the relevant clinical skills required to perform the designed tasks. The cases were developed on the following themes (common public health problems in Saudi Arabia): Arthritis, Hypertension, Type 2 Diabetes Mellitus, Polypharmacy, and Depression. Pharmacists were randomly divided into several small groups (4-5 per group). Each pharmacist within the group was exposed to different clinical scenarios and assigned a list of assessment tasks, which they needed to perform (see Table 1). Pharmacists then completed a questionnaire about their attitudes and perceptions of the PBL - case method at the end of the PBL sessions (after 2 months).

\section{Assessment parameter}

Clinical assessments and activities were performed on mock patients. Knowledge versus performance activities designed for $1: 0.5$ ratio (90 $\mathrm{min})$.

\section{Evaluation survey}

To evaluate the clinical skills, two separate measurements were performed. First, activity scores were measured via the PBL Clinical Skill Grading Rubric (see Table 1). Next, pharmacists completed a skill perception survey. The aims of the survey were to evaluate the degree to which the PBL objectives were met.

Items included in the survey-evaluated pharmacists' knowledge of the presented case, their attitude to use the data and perceptions on their performance of clinical assessment. Some of the included items also estimated overall PBL value and confidence of the pharmacists to perform clinical assessment or activity.

Skills and attitudes were measured at both the knowledge and the practical levels. An assessment and a survey were developed to measure the pharmacist's clinical skills as well as their opinion of the value of the case-based knowledge and clinical assessments. Similarly, an assessment and survey were used to evaluate clinical skills and perceptions of practical performance and the pharmacists' perceived value of the knowledge as well as the PBL-case methodology.

\section{Validation and reliability of survey questionnaire}

Draft of the survey was first given to the instructors $(N=15)$ for their suggestions on the appropriatness, clarity and quality of the included items. After minors corrections final survey was administered to a pharmacist group. To measure the reliability of the survey's internal consistency, 
Cronbach's alpha test was used by comparing the score for each item with the total score for the survey. Cronbach's alpha reliability coefficient for case data recitation (Table 3 ) is 0.91 and Clinical assessment skills (Table 4) coefficient is 0.89 .

\section{Statistical analysis}

Data were collected using a 5 - Likert scale questionnaire (strongly disagree - strongly agree). The questionnaire asked questions about pharmacist perceptions of clinical services. Data was analyzed by Statistical Package for Social Sciences (SPSS) 22 (B) for Windows. An independent sample t-test was used to compare mean differences between groups on continuous variables. A statistical significance level of 0.05 was used for this analysis.

\section{RESULTS}

All two- hundred \& fifty-five pharmacists completed the questionnaire survey at the end of PBL sessions. In summary, pharmacists reported to "agree" with their knowledge-level understanding of cases taught following $\mathrm{PBL}$ method (4.01 \pm 0.67$)$, with a positive evaluation of their ability to perform clinical data assessment $(4.48 \pm 0.58)$.

A significant difference was found in terms of gender with regard to "valuing" the content of PBL session associated with clinical skill assessment or tasks. The study sample comprised 128 (50.9\%) males and 127 (49.1\%)

females, but the mean score for male was 47.91 \pm 7.15 and $50.31 \pm 4.88$ (Table 2).

Cronbach's alpha reliability coefficient for case data recitation (Table 3 ) is 0.91 and Clinical assessment skills (Table 4) coefficient is 0.89 . Overall, pharmacists reported that they "agree" $(4.01 \pm 0.67)$ with their ability to use case data recitation taught in the $\mathrm{PBL}-$ series, they also reported a positive evaluation (4.48 \pm 0.58$)$ of their ability to perform clinical data assessment. Significant difference was also found between the genders in terms of "valuing" the content of PBL session associated with clinical skill assessment/tasks. Gender differences were also observed in terms of pharmacist self-confidence (Table 4). In addition, pharmacists' selfconfidence with regard to $\mathrm{PBL}$ was statistically significant among gender (Table 5).

Table 1: $P B L$ clinical skill grading rubric

\begin{tabular}{lc}
\hline Category & Score \\
\hline Developing goals of therapy & 5 \\
Base knowledge on drug use & 5 \\
Drug dose adjustment techniques & 10 \\
Drug use counseling for Side effects & 5 \\
Treatment monitoring plan & 10 \\
Purpose of monitoring tests & 5 \\
Defining critical symptoms with drug & 5 \\
use for referral & 5 \\
Clinical assessment for suggesting & 10 \\
alternative therapies & \\
Evidence / reference for alternative & \\
therapies & \\
\hline Total Score & 60 \\
\hline
\end{tabular}

Table 2: Mean $( \pm S D)$ scores for clinical skills based on gender $(n=255)$

\begin{tabular}{lcccc}
\hline \multirow{2}{*}{ Category } & \multicolumn{2}{c}{ Male } & \multicolumn{2}{c}{ Female } \\
\cline { 2 - 5 } & Mean & SD & Mean & SD \\
\hline Developing goals of therapy & 4.01 & 0.70 & 4.45 & 0.73 \\
Base knowledge on drug use* & 3.65 & 0.79 & 4.32 & 0.78 \\
Drug dose adjustment techniques & 6.71 & 1.14 & 8.82 & 1.01 \\
Drug use counseling for Side effects & 3.82 & 0.65 & 4.23 & 0.52 \\
Treatment monitoring plan & 6.98 & 0.61 & 9.05 & 0.77 \\
Purpose of monitoring tests & 3.77 & 1.00 & 3.85 & 0.88 \\
Defining critical symptoms with drug use for referral & 4.25 & 0.55 & 4.37 & 0.65 \\
Clinical assessment for suggesting alternative therapies * & 3.14 & 0.41 & 3.98 & 0.76 \\
Evidence / reference for alternative therapies & 7.38 & 1.23 & 8.91 & 0.85 \\
Total score & 47.91 & 7.15 & 50.31 & 4.88 \\
\hline
\end{tabular}

${ }^{*}$ Denotes statistically significantly difference between genders $(p<0.05)$.

\section{DISCUSSION}

A well-structured pharmacy curriculum must impart education and training which are mandatory to develop core clinical knowledge, positive attitude and other required skills to practice with confidence in real-time work environment. Pharmacy graduates must have both effective communication and clinical skills. [7-9] In contrast, pharmacy teaching and education literature lack information about how to teach pharmacists to value knowledge and performance skills (e.g., PBL, OSCE, OSPE). [10] This study's findings provide extensive information about how to develop or modify 
Table 3: Pharmacists' perception of knowledge and methodology by rank order $(n=255)$

\begin{tabular}{llll}
\hline \multirow{2}{*}{ Rank } & Item & \multicolumn{2}{c}{ Likert Scale } \\
\cline { 3 - 4 } & & Mean & SD \\
\hline 1 & I can perform an effective patient interview & 4.39 & 0.59 \\
2 & I can assess the information of case medical history & $4.31^{*}$ & 0.58 \\
3 & I can develop the therapeutic goals with case data & 4.12 & 0.61 \\
4 & I can discuss the medical history of selected diseases taught in PBL & 3.89 & 0.62 \\
& session & $3.85^{*}$ & 0.78 \\
5 & I can develop a therapeutic care plan & 3.77 & 0.85 \\
7 & I understand how to perform counseling on drug use & 3.72 & 0.66 \\
8 & I can communicate both verbally and written form & 3.69 & 0.99 \\
9 & I can monitor patient's drug therapy based on disease outcome & $3.52^{*}$ & 0.76 \\
10 & I can perform clinical literature search to obtain pertinent information & $3.48^{*}$ & 0.89 \\
11 & I can use laboratory data to make therapy decisions & 3.31 & 1.00 \\
\hline
\end{tabular}

Recitation scale: 5 = strongly agree; 4 = agree; 3 = uncertain; 2 = disagree; $1=$ strongly disagree. ${ }^{*}$ Denotes statistically significantly difference between genders $(p<0.05)$

Table 4: Clinical assessment skills evaluation by rank order $(n=255)$

\begin{tabular}{llll}
\hline & & \multicolumn{2}{c}{ Likert scale } \\
\cline { 3 - 4 } Rank & Item & Mean & SD \\
\hline 1 & I cannot compile the patient history data & 4.59 & 0.59 \\
2 & I can perform clinical data assessment & $4.48^{*}$ & 0.58 \\
3 & I can correlate clinical outcomes with drug therapy & 4.32 & 0.61 \\
4 & I cannot perform the effective counseling on side effects & $3.99^{*}$ & 0.62 \\
5 & I cannot determine the critical points of GP referral & 3.95 & 0.78 \\
6 & I can identify the drug related problems & $3.88^{*}$ & 0.85 \\
7 & I can develop and implement pharmaceutical care plan & 3.81 & 0.66 \\
8 & I can develop the rational for clinical assessment & 3.72 & 0.99 \\
9 & I cannot perform general physical examination & $3.42^{*}$ & 0.76 \\
10 & I can perform effectively in drug information section & $3.38^{*}$ & 0.89 \\
\hline
\end{tabular}

Clinical skill assessment scale: 5-point Likert agreement scale, negative items have been reverse scored so that a higher score reflects greater ability. Clinical skill assessment scale: $5=$ strongly agree; 4 = agree; $3=$ uncertain; 2 = disagree; 1 = strongly disagree. ${ }^{*}$ Denotes statistically significantly difference between genders $(p<0.05)$

Table 5: Pharmacists' evaluation of PBL: Value and confidence $(n=255)$

\begin{tabular}{|c|c|c|}
\hline \multirow[b]{2}{*}{ Item } & \multicolumn{2}{|c|}{ Likert Score } \\
\hline & Mean & $S D$ \\
\hline $\begin{array}{l}\text { How you describe the value of case } \\
\text { data of PBL? }\end{array}$ & 3.51 & 0.99 \\
\hline $\begin{array}{l}\text { How you describe the value of } \\
\text { clinical skill assessment activities of } \\
\text { PBL? }\end{array}$ & $3.97^{*}$ & 1.11 \\
\hline $\begin{array}{l}\text { What is your level of confidence to } \\
\text { perform clinical assessment tasks } \\
\text { /activities? }\end{array}$ & $3.04^{*}$ & 1.19 \\
\hline $\begin{array}{l}\text { What is your level of confidence } \\
\text { towards PBL instructor's clinical } \\
\text { assessment skill? }\end{array}$ & 4.35 & 0.65 \\
\hline \multicolumn{3}{|c|}{$\begin{array}{l}\text { Value scale: } 5=\text { extremely valuable; } 4=\text { very valuable; } \\
3=\text { valuable; } 2=\text { somewhat valuable; } 1=\text { not valuable. } \\
\text { Confidence scale: } 5=\text { extremely confident; } 4=\text { very } \\
\text { confident; } 3=\text { confident; } 2=\text { somewhat confident; } 1= \\
\text { not confident. }{ }^{*} \text { Denotes statistically significantly } \\
\text { difference between genders }(p<0.05)\end{array}$} \\
\hline
\end{tabular}

instruction using the PBL case study methodology in order to better serve the patients and provide clinical services.

The findings showed pharmacists' overall clinical knowledge on pharmaceutical care tasks. There is a significant difference in mean knowledge score with regard to gender; on further analysis, the findings showed a significant difference in mean knowledge score for basic knowledge about drug use $(p<0.001)$, drug use counseling for side effects $(p<0.000)$, and clinical performance concerning alternative therapies $(p$ $<$ 0.011). Crawford and colleagues [11] presented evidence on gender-based preferred learning styles and fostering pharmacist success through performance-based skills such as communication, problem-solving, critical thinking, and interpersonal skills.

Wasif et al [12] also showed that genders differed in learning style and outcome, based on the design of pharmacy curricular activities and training. This study suggests that the current pharmacy curriculum should encourage the 
development of pharmacist practitioners who are motivated to implement the concept of pharmaceutical care in their practice. This finding is consistent with other studies conducted in the United States [13], Nigeria [14] and Pakistan [15], where pharmacists are well-disposed towards the concept. Pharmacy professional training must provide graduates with adequate knowledge, skills, and positive attitude toward learning that promotes the assumption of selfconfidence for performing pharmaceutical care services [16].

This PBL course was designed around the competency statement to "design, implement, evaluate, and modify" patient pharmacotherapy based on scientific principles to ensure effective, safe and economical patient care [17]. Pharmacists generally rated themselves as experts at the knowledge level for effective patient interview, clinical assessment of drug therapies, and predicting clinical outcomes with drug therapies. According to Bloom's taxonomy, the acquisition of knowledge required to recite or describe demands lower cognitive thinking skills than the ability to apply or perform tasks related to that knowledge [18]. The PBL Case model is designed to move pharmacists from the knowledge level to the application level. This correlates with the higher confidence levels at the knowledge level in the study.

In a country such as Saudi Arabia, where the burden of chronic diseases, such as obesity [1819] and diabetes [20], is increasing among the population, pharmacists can contribute to increasing public awareness about these emerging epidemics [21]. This finding reflects the success of pharmaceutical care skills as well as development of professional maturity as the pharmacists engage in experimental training and learning.

However, pharmacists rating of the value of the PBL course was lower than expected. We do not know if the problem is "that they do not see its application to practicing pharmacy or the organization of the course needs improving." [22] This suggests that pharmacists did not have issues with the course content or structure. Perhaps, the pharmacists were not used to PBL as a new style of teaching; however they might have benefitted from it without realizing it.

Identifying barriers that limit pharmaceutical care services in pharmacy services are warranted in Saudi Arabia. Studies performed in developed countires intendified various barriers as obstacles in implementation of better pharmaceutical care. [18-22]. Pharmacists often complain about lack of time for clinical assessment but this can be overcome by efficient distribution of tasks between pharmacists and the pharmacy technicians. Moreover, in Saudi Arabia there is a need to create a working environment where a pharmacist can work closely with physicians and other health care professionals in hospital wards and clinics. This would help to build rapport and physicians' trust in pharmacists and eventually promote pharmacist role in multi-health care teams.

\section{Limitations of the study}

a. Limited resources and site of research may lead to non-generalized conclusion.

b. Participants with limited interest and reduce exposure to pharmaceutical care services showed low confidence in the care process.

c. It would have been better to adapt randomized case-control methodology to present the findings for multicenter research.

d. Current PBL sessions in place need to be reformatted systemically so that pharmacists value the material as well.

\section{CONCLUSION}

The findings of this study indicate that overall, pharmacists' self-confidence in their ability to perform clinical pharmacy services is low. However, female pharmacists possess better clinical knowledge and practical skill levels for pharmaceutical care when compared to men. Furthermore, pharmacists placed low value on PBL method, indicating that extensive restructuring of the current method is required to improve their level of confidence in their ability to provide quality care after PBL.

\section{DECLARATIONS}

\section{Conflict of Interest}

The authors declare that they have no conflict of interest to disclose with regard to this work.

\section{Authors' contribution}

We declare that this work was done by the authors named in this article and all liabilities pertaining to claims relating to the content of this article will be borne by the authors. 


\section{REFERENCES}

1. Hepler $C D$. The future of pharmacy: pharmaceutical care. Am Pharm 1990; NS30 (10): 23-29.

2. American Society of Hospital Pharmacists. ASHP statement on Pharmaceutical care. Am J Hosp Pharm 1993: 50: 1720- 1723.

3. Berenguer B La, Casa C de La, Matta MJ, Martin-Calero MJ. Pharmaceutical care: the past, present, and future. Curr Pharm Des 2004; 10(31): 3931-3946.

4. Joint Commission of Pharmacy Practitioners. Pharmacists' Patient Care Process. May 29, 2014. Accessed: 9-09-2016. Web link http://www.pharmacist.com/sites/default/files/files/Patien tCareProcess.pdf

5. Chisholm MA, Wade WE. Factors influencing pharmacists' attitudes toward pharmaceutical care. Am J Health Syst Pharm 1999; 56(22): 2330-2335.

6. ACPE. Guidance for standards 2016. ACPE, Chicago, Illinois. 2015. Accessed: 9-09-2016. https://www.acpeaccredit.org/pdf/GuidanceforStandards2016FINAL.pdf

7. Hurd PD. Questions and critical thinking. Am J Pharm Educ 1994; 58, 422- 423 "article."

8. Parkhurst C. Assessing and improving pharmacists' verbal communication abilities in pharmacy courses. Am J Pharm Educ 1994; 58, 50-55.

9. Hunter KA. Poster presentations: an alternative to traditional classroom lecture. Am J Pharm Educ 1997; $61,78-80$

10. Krathwothal DR, Bloom BS. Taxonomy of Educational Objectives, Handbook 1: Cognitive, Longman Group, United Kingdom 1984.

11. Crawford $S Y$, Alhreish $S K$, Popovich N G. Comparison of Learning Styles of Pharmacy Pharmacists and Faculty Members. Am J Pharm Educ 2012; 76(10), Article 192. http: //doi.org/10.5688/ajpe7610192

12. Wasif $S$ G, Azhar S S, Norhayati I, Azmi S, Yelly OS. The development of PILS scoring system for the assessment of teaching techniques. Pharmacy education 2011; 11(1): 78-84.

13. Udeogaranya PO, Uwe CV, Ekwunife OI. Assessment of attitudes of the university of Nigeria pharmacy pharmacists toward pharmaceutical care. Pharm Pract (Granada) 2009; 7(3): 145-149.

14. Rahim N, Nesar S. Pharmacy undergraduate pharmacists' attitude toward pharmaceutical care in Pakistan. Int J Pharm Pharm Sci 2012; 4(4): 113-116.

15. Martin $B C$, Chisholm $M A$. Cross-validation of an instrument measuring pharmacists attitudes toward pharmaceutical care. Am J Pharm Educ 1999; 63(1): 4651.

16. Adamick B A. Teaching pharmaceutical care: Removing the fences. Am J Pharm Educ 1992; 56: 434-441.

17. Gallagher RM, Gallagher HC. Improving the working relationship between doctors and pharmacists: is interprofessional education the answer? Adv Health Sci Educ Theory Pract 2012; 17(2): 247-257. doi: 10.1007/s10459-010-9260-5

18. Perraudin C, Brion F, Bourdon O, Pelletier-Fleury N. The future of pharmaceutical care in France: a survey of final-year pharmacy pharmacists' opinions. BMC Clin Pharmacol 2011; 11: 6. doi: 10.1186/1472-6904-11-6

19. Matowe L. Use of personal digital assistants for instant access to drug information Med Princ Pract 2004; 13(5): 290- 291.

20. Al Rashdan I, Al Nesef Y. Prevalence of overweight, obesity, and metabolic syndrome among adult Kuwaitis: results from the community-based national survey. Angiology 2010; 61(1): 42-48. doi: 10.1177/0003319709333226

21. Moussa MA, Alsaeid M, Abdella N, Refai TM, Al-Sheikh $N$, Gomez JE. Prevalence of type 2 diabetes mellitus among Kuwaiti children and adolescents. Med Princ Pract 2008; 17(4):270-275. doi: 10.1159/000129604

22. May JR. Barriers to pharmaceutical care in the acute care setting. Am J Hosp Pharm 1993; 50(8): 1608-1611. 